\title{
Laboratory Investigation of the Role of Desorption Kinetics on Americium Transport Associated with Bentonite Colloids
}

Timothy Mark Dittrich ${ }^{\mathrm{a}, *}$, Hakim Boukhalfa ${ }^{\mathrm{a}}$, Stuart Douglas Ware ${ }^{\mathrm{a}}$, and Paul William Reimus ${ }^{\mathrm{a}}$

${ }^{a}$ Earth and Environmental Sciences Division, Los Alamos National Laboratory, P.O. Box 1663, Mail Stop J966, Los Alamos, NM 87545, USA

* Corresponding author: Los Alamos National Laboratory, P.O. Box 1663, Mail Stop J966, Los Alamos, NM 87545 Tel: 505-665-2100, Fax: 505-606-2258. E-mail addresses: timdittrich@lanl.gov, hakim@lanl.gov,

dware@lanl.gov,preimus@lanl.gov 


\section{Abstract}

Understanding the parameters that control colloid-mediated transport of radionuclides is important for the safe disposal of used nuclear fuel. We report an experimental and reactive transport modeling examination of americium transport in a groundwater-bentonite-fracture fill material system. A series of batch sorption and column transport experiments were conducted to determine the role of desorption kinetics from bentonite colloids in the transport of americium through fracture materials. We used fracture fill material from a shear zone in altered granodiorite collected from the Grimsel Test Site (GTS) in Switzerland and colloidal suspensions generated from FEBEX bentonite, a potential repository backfill material. The colloidal suspension $\left(100 \mathrm{mg} \mathrm{L}^{-1}\right)$ was prepared in synthetic groundwater that matched the natural water chemistry at GTS and was spiked with $5.5 \times 10^{-10} \mathrm{M}^{241} \mathrm{Am}$. Batch characterizations indicated that $97 \%$ of the americium in the stock suspension was adsorbed to the colloids. Breakthrough experiments conducted by injecting the americium colloidal suspension through three identical columns in series, each with mean residence times of 6 hours, show that more than $95 \%$ of the bentonite colloids were transported through each of the columns, with modeled colloid filtration rates $\left(k_{f}\right)$ of 0.01-0.02 $\mathrm{h}^{-1}$. Am recoveries in each column were 55 to $60 \%$, and Am desorption rate constants from the colloids, determined from 1-D transport modeling, were $0.96,0.98$, and $0.91 \mathrm{~h}^{-1}$ in the three columns, respectively. The consistency in Am recoveries and desorption rate constants in each column indicates that the Am was not associated with binding sites of widely-varying strengths on the colloids, as one binding site with fast kinetics represented the system accurately for all three sequential columns. Our data suggest that colloid-mediated transport of Am in a bentonite-fracture fill material system is unlikely to result in transport over 

Am strongly-associated with the colloids.

26

Keywords: americium; granite/granodiorite; reactive transport; desorption kinetics; column experiments; bentonite colloids

29

30 6 37 38 39 40 1

\section{Abbreviations}

GTS: Grimsel Test Site

FFM: Fracture fill material

SZW: Shear zone water

LANL: Los Alamos National Laboratory

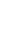
2 3 


\section{Introduction}

Safe disposal of radioactive waste is a concern for many countries around the world. Burial in deep geologic repositories is one strategy that has been investigated with the idea that waste packages would be isolated with natural and engineered barriers to prevent leakage until the radioactivity has largely decayed. Although laboratory experiments (Dittrich and Reimus, 2015; Huber et al., 2011; Schäfer et al., 2012) and field studies (Geckeis et al., 2004; Kersting et al., 1999; Kurosawa et al., 2006; Möri et al., 2003; Wang et al., 2014b; 2013a) have been conducted to evaluate radionuclide colloid-facilitated transport, uncertainty remains regarding the potential transport of strongly sorbing radionuclides associated with mobile colloidal particles (Baston et al., 1994; Dittrich, 2012; Schäfer and Noseck, 2010; Wold, 2010). Reliable data concerning americium $(\mathrm{Am})$ transport in association with bentonite colloids through geochemically altered granite materials is relatively sparse and is the focus of this paper.

Field experiments and environmental monitoring observations have shown that Am transport can be enhanced by the presence of colloids. Penrose et al. (1990) found Am released as part of a treated waste stream into a canyon at Los Alamos National Laboratory was detected over $3 \mathrm{~km}$ from the source and was associated very strongly with colloids in the $25-430 \mathrm{~nm}$ size range. However, some uncertainty remains concerning the exact mechanism of Am and Pu transport documented for the Los Alamos site (Marty et al., 1997). Geckeis et al. (2004) conducted two in situ experiments at the Grimsel Test Site (GTS) in Switzerland by injecting radionuclides adsorbed to bentonite colloids in a fractured shear zone and found that most of the $\mathrm{Am}$ and $\mathrm{Pu}$ migrated without retardation in association with colloids. In their experiment, significant transport of both $\mathrm{Am}$ and $\mathrm{Pu}$ were attributed to slow desorption kinetics from mobile colloids. Up to $60 \%$ of the Am was removed from collected samples by centrifugation, suggesting either intrinsic Am colloids or Am sorbed to natural colloids played a role in transport. Vilks and Baik 
(2001) investigated Am transport through a natural fracture in a granite block and found that dissolved Am was completely adsorbed to fracture surfaces, but injecting dissolved Am and colloids together resulted in small but measurable transport.

Laboratory experiments with Am, granite, and bentonite colloids have demonstrated the need for more quantitative analysis to determine the role of desorption rates in Am transport. Kunze et al. (2008) found that FEBEX bentonite and Grimsel groundwater form stable colloids with an average diameter of $30 \mathrm{~nm}$, and Liu and Neretnieks (2006) summarize the conditions that promote the generation and transport of bentonite colloids from engineered buffer systems. Murali and Mathur (2002) investigated Am adsorption to bentonite and granite as a function of contact time, $\mathrm{pH}$, liquid-solid ratio, radionuclide concentration, and the presence of competing cations and found that Freundlich and Langmuir isotherms seem to accurately predict Am/bentonite sorption. Iijima et al. (2008) attributed differences in reported Am effective retardation factors for colloid-facilitated transport $\left(R_{d}\right)$ to differences in solution composition and reaction site density. Iijima et al. (2010) investigated the effect of addition order on sorption rate coefficients and reversibility in batch experiments with Am, GTS granite, and bentonite colloids and found Am adsorption to bentonite to be reversible and independent of addition order. The sorption behavior was described well by a surface complexation and ion exchange model. Distribution coefficients for americium and bentonite clays reported in the literature for $\mathrm{pH}$ values ranging from 8-10 are summarized in Table 1. Flügge et al. (2010) and Huber et al. (2011) also investigated Am adsorption and desorption in the ternary system containing GTS groundwater, GTS fracture fill material (FFM) and bentonite colloids, and reported Am desorption rates of $1.4 \times 10^{-9} \mathrm{M}$ and $8.0 \times 10^{-9} \mathrm{M}$ of $0.009 \mathrm{hr}^{-1}$ and $0.0037 \mathrm{hr}^{-1}$ for initial Am concentrations of $1.4 \times 10^{-9} \mathrm{M}$ and $8.0 \times 10^{-9} \mathrm{M}$, respectively. Linear free energy relationships 
(LFERs) have also been developed for Am sorption with montmorillonite and illite (Bradbury and Baeyens, 2005a; 2005b; 2006; 2009) and they suggest a distribution of binding sites based on complexation and ion exchange.

The objective of this study was to quantify Am colloid-facilitated transport through a geochemically altered granodiorite system to provide insights into upscaling in space and time, which are important in repository risk assessment calculations. Americium was adsorbed to bentonite clay colloids before injection through columns packed with fracture fill material to quantify the desorption rate constants that characterize Am release from bentonite colloids. We selected a fractured/weathered granodiorite at the Grimsel Test Site (GTS) in Switzerland as a model crystalline rock repository system because the system has been thoroughly studied (Dittrich and Reimus, 2013; Huber et al., 2011; Missana et al., 2004), and field experiments involving actinides have already been conducted at this site (Geckeis et al., 2004; Wang et al., 2014b; 2013a).

\section{Materials and Methods}

A bentonite colloid suspension in synthetic Grimsel groundwater spiked with trace levels of ${ }^{241} \mathrm{Am}$ was successively injected through a series of three identically-prepared small columns that were packed with the GTS fracture fill material. A fraction of the effluent collected at the outlet of each column was used for analysis and the remainder was injected through a fresh column. This repeat injection procedure was conducted to determine if colloids that transported through one column were more likely to transport through a second and third column, and more importantly, to determine if Am that transported through one column in association with bentonite colloids was more likely to remain associated with the colloids and transport more efficiently through a second and third column. If either of these outcomes were observed, it 
would suggest a distribution of colloid filtration rate constants and/or a distribution of Am desorption rate constants from colloids, which would have important implications for the scale dependence of colloid-facilitated transport of Am. In effect, the repeat-injection experiments were designed to interrogate slow colloid filtration rates and slow desorption rates better than single-pass experiments and to effectively allow intermediate distance sampling. Slow rates have a much greater influence on large-scale performance assessment calculations of colloidfacilitated transport than faster rates (Wang et al., 2014a). However, faster rates can mask the presence of slower rates when there is a distribution of rates, particularly in a single-pass column experiment.

\subsection{Groundwater}

The groundwater used in all experiments was synthetic shear zone water (SZW) that matched the chemistry of the water found in the shear zone at the Grimsel Test Site (Huber et al, 2011; Missana et al., 2004). The SZW was prepared by adding analytical grade reagents to filtered, high-purity water (> $18 \mathrm{M} \Omega \mathrm{cm}$ resistivity) to achieve the elemental concentrations of constituents listed in Table 2. The ionic strength $(0.66 \mathrm{mM})$ was calculated from the added reagents and $\mathrm{pH} 8.0$ was measured for the solution equilibrated with the atmosphere in Los Alamos, NM (2,231 $\mathrm{m}$ above sea level). The carbonate concentration listed in Table 2 is for the SZW as prepared, not after equilibration with the atmosphere. Although the actual SZW has a reducing redox potential, these experiments were conducted in contact with the atmosphere. Americium occurs as Am(III) under both oxidizing and reducing conditions and the infiltration of an oxidizing water at some future time in an otherwise reducing crystalline rock environment is possible under the influence of climate change or disruptive event scenarios. 


\subsection{Porous Medium}

Weathered fracture fill material (also known as fault gouge) was collected by coring the MI shear zone at the Grimsel Test Site (GTS) in Switzerland. The shear zone occurs where local stresses caused the two surfaces of a fracture in the granite/granodiorite parent rock to slip past each other and exposure to hydrothermal solutions resulted in geochemical alteration of the surfaces over time. Samples were shipped to Los Alamos National Laboratory (LANL) in pieces ranging from micron size up to $10-15 \mathrm{~cm}$ long. All material provided was less than $2 \mathrm{~cm}$ thick and was visibly altered from the parent granodiorite. This alteration was apparent from the uniform grey nature of the material on the surface and interior of the pieces, as opposed to the bight white appearance of the parent granodiorite (Dittrich and Reimus, 2015; Dittrich and Reimus, 2015). Due to the small quantity of material less than $0.5 \mathrm{~mm}$, all pieces less than $1 \mathrm{~cm}$ in size were crushed using a percussion mortar, sorted (75-150, 150-355, and 355-500 $\mu \mathrm{m}$ size fractions), and thoroughly rinsed in high-purity water to remove all fines (particles $<75 \mu \mathrm{m}$ ). The samples were then rinsed with SZW until the electrical conductivity of the solution in contact with the material for 24 hours was within $5 \%$ of the electrical conductivity of the SZW. Samples were then oven dried for 12 hours at $60^{\circ} \mathrm{C}$ and stored. Optical microscope (Wild Heerbrugg, M420) and SEM (JEOL 6300 FXV) images of the 150-355 $\mu \mathrm{m}$ size fraction of the FFM show the varied shape and color of grains with rough surfaces and layered edges (Fig. 1). Unaltered granodiorite microphotos are shown in Dittrich and Reimus (2015). The mineralogy of the granodiorite and FFM was determined by quantitative X-ray diffraction (QXRD) at LANL. Table 3 lists the major mineral fractions for the unaltered granodiorite, a scraping from the shear zone surface, and a bulk sample of the crushed FFM that we used in our experiments. The main mineralogical difference between the unaltered granodiorite and the fracture fill material is a significant reduction in quartz and microcline and 
significant increase in muscovite and biotite in the FFM. The data of Table 3 also show that while the homogenized crushed FFM sample differed somewhat in mineralogy from the small scraping taken from the shear zone surface, it much more closely resembled the mineralogy of the altered surface than the parent granodiorite. Chemical analyses of the bulk granodiorite and FFM by X-ray florescence (XRF) and energy dispersive x-ray spectroscopy (EDS) were previously reported (Dittrich and Reimus, 2015; Dittrich et al., 2015a; Wang et al., 2013b) with a significant enrichment in $\mathrm{Mg}$, minor enrichment in $\mathrm{K}$ and $\mathrm{Fe}$, and minor depletions of $\mathrm{Si}, \mathrm{Na}, \mathrm{Ca}$, and $\mathrm{Sr}$ in the FFM. The FFM surface area used in our experiments was determined by a krypton BET method (Micromeritics Analytical Services) to be $0.23 \mathrm{~m}^{2} \mathrm{~g}^{-1}$ for the $150-355 \mu \mathrm{m}$ size fraction. The surface area of the $150-355 \mu \mathrm{m}$ size fraction of bulk granodiorite was reported as $0.1 \mathrm{~m}^{2} \mathrm{~g}^{-1}$ in Dittrich and Reimus (2015), indicating that the same crushing and sieving procedure resulted in about twice the specific surface area of FFM relative to the parent granodiorite for the same nominal particle size fraction.

\subsection{Bentonite Colloids}

Bentonite colloids were processed from a brick of compressed FEBEX bentonite provided by colleagues at GTS. Samples of the brick were crushed in a ceramic mortar and pestle and dry Sieved to retain the size fraction less than $75 \mu \mathrm{m}$. The bentonite particles were then sodium saturated to enable comparison of our results with other published results (e.g., Huber et al., 2011). The process is described in detail in Appendix A with images of each step (Figure A.1).

The sodium-saturated and SZW-equilibrated suspension was then diluted and settled in graduated cylinders for 2 weeks (Figure A.1) to obtain a theoretical particle size of less than 1 $\mu \mathrm{m}$ based on Stokes' Law calculations. The final stock suspension was then passed through a $0.80 \mu \mathrm{m}$ filter to remove any aggregated particles. The colloid counts and size distribution were 
determined using a laser particle spectrometer (Particle Measuring Systems, Inc.). The spectrometer counts and sizes individual colloids by passing a diluted sample stream through a laser beam. Very few particles larger than $220 \mu \mathrm{m}$ were present (Figure A.2). The concentration of the stock suspension was calculated to be $\left(1540 \mathrm{mg} \mathrm{L}^{-1}\right)$ by drying $25.0 \mathrm{~g}$ of suspension on a watch glass (in triplicate) and determining the weight difference after drying. The stock suspension was diluted to $100 \mathrm{mg} \mathrm{L}^{-1}$ and was stored in a sealed glass bottle. Surface area was measured to be $56.1 \mathrm{~m}^{2} \mathrm{~g}^{-1}$ using a nitrogen BET method (Micromeritics Analytical Services).

\subsection{Americium and Tritiated Water}

${ }^{241}$ Am stock solution was purchased from Eckert and Ziegler Isotope Products (Valencia, CA). The Am was processed by the supplier within 3 weeks of ordering, stabilized in $\mathrm{HCl}$, and was reported to be $>99.8 \%{ }^{241} \mathrm{Am}$ with very little ingrowth of ${ }^{137} \mathrm{~Np}$. SZW with $100 \mathrm{mg} \mathrm{L}^{-1}$ concentration of bentonite colloids was spiked with $5.5 \times 10^{-10} \mathrm{M}^{241} \mathrm{Am}$ (See Appendix B). The suspensions were allowed to equilibrate for 1 week. Chemical speciation calculations using the HCh software package (Bastrakov, 1999) for SZW water chemistry at $\mathrm{pH} 8$ determined $\mathrm{AmCO}_{3}{ }^{+}$ and $\mathrm{Am}\left(\mathrm{CO}_{3}\right)_{2}{ }^{-}$as the dominant species, which has been also been reported by others (e.g., Iijima et al., 2008). All suspensions were stored in Teflon ${ }^{\circledR}$ bottles. It should be noted that we attempted to make a $5.5 \times 10^{-10} \mathrm{M}$ solution of dissolved Am without colloids and over $75 \%$ of the ${ }^{241} \mathrm{Am}$ was lost to the bottle surfaces, resulting in less than $25 \%$ of the original Am remaining in solution (Fig. B.1). This difficulty has been reported by others (e.g., Degueldre et al.,1994). When Am solution was added to the bentonite colloidal suspension, all of the Am remained in the suspension, with $>97 \%$ being sorbed to the colloids and $<3 \%$ remaining in the dissolved phase with no measurable sorption to the bottle surfaces. Stock suspensions were measured for 3 months and remained stable without any measureable loss of Am. 
Tritium in the form of tritiated water was added to the Am and bentonite suspensions as a conservative tracer to provide residence times and dispersivities in the column experiments.

\subsection{Analytical Measurements}

${ }^{241} \mathrm{Am}$ and tritium concentrations were measured by liquid scintillation counting (LSC, Perkin Elmer, Tri-Carb 2550) with energy ranges of 0-20 keV for tritium and 100-250 keV for Am. A $1.0 \mathrm{~mL}$ aliquot of sample was combined with $5.0 \mathrm{~mL}$ of high-purity water and $14.0 \mathrm{~mL}$ of liquid scintillation cocktail (Packard, Ultima Gold AB) in a polypropylene scintillation vial to yield $20.0 \mathrm{~mL}$ total. The vial was vigorously shaken for at least 15 seconds to ensure mixing and each vial was counted for 30 minutes. The transformed spectral index of an external ${ }^{133} \mathrm{Ba}$ standard (tSIE) was used to correct for variable quenching of the samples, which was particularly important for accurate determination of tritium.

Total ${ }^{241} \mathrm{Am}$ concentrations were measured using uncentrifuged column effluent and dissolved ${ }^{241} \mathrm{Am}$ was measured by centrifuging the sample at $8,900 \mathrm{~g}$ for 3.5 hours and then analyzing $1.0 \mathrm{~mL}$ of the supernatant for ${ }^{241} \mathrm{Am}$ concentration. Colloid-associated ${ }^{241} \mathrm{Am}$ was then calculated as the difference between the total Am concentration and the Am concentration remaining in solution after centrifugation.

The $\mathrm{pH}$ of the solutions and suspensions were measured using a $\mathrm{pH}$ meter (Orion, Model 290) and a glass $\mathrm{pH}$ electrode (Fisher, AccupHast) calibrated with 4.01, 7.00, and $9.01 \mathrm{pH}$ buffer solutions (Ricca Chemical Corp.).

Colloid concentrations of the bentonite suspensions were measured using a turbidimeter (Hach, 2100N), which was calibrated with standards $\left(0.1,1,5,10,20,40,60,80,100 \mathrm{mg} \mathrm{L}^{-1}\right)$. The same $12 \mathrm{~mm}$ borosilicate glass test tube was used for every measurement to reduce error from test tube variability. Colloid concentration was calculated using a correlation function 
derived to relate colloid concentration $\left(\mathrm{mg} \mathrm{L}^{-1}\right)$ with the measured NTU (nephelometric turbidity units) of the sample.

\subsection{Column Transport Experiments}

Americium column transport experiments were conducted by eluting Am and bentonite suspensions through columns packed with FFM in the 150-355 $\mu \mathrm{m}$ size range. Small columns were constructed from $6 \mathrm{~cm}$ lengths of $0.95 \mathrm{~cm}$ diameter Teflon ${ }^{\circledR}$ tubing. The ends of the tubes were tapped to accept Teflon ${ }^{\circledR}$ compression fittings. The inside openings were covered with a small disk of $75 \mu \mathrm{m}$ polyetheretherketone (PEEK) screen to retain the column material while providing minimum resistance to flow and causing negligible straining of colloids. Teflon ${ }^{\circledR}$ tubing (1.59 mm ID) and 3-way polycarbonate stopcocks were used to connect the columns to 50 mL Teflon ${ }^{\circledR}$ syringes (Torviq, TS-50) adapted for use with syringe pumps (KD Scientific, Model 100). The use of 3-way stopcocks allowed for refilling syringes and switching suspensions or solutions while minimizing flow and pressure disturbances that may affect colloid retention. Column flow was directed upward and an additional length of $1.59 \mathrm{~mm}$ ID Teflon ${ }^{\circledR}$ tubing was connected to the outlet side of the column and directed to a fraction collector (Gilson, FC-220) filled with $13 \times 100 \mathrm{~mm}$ polystyrene test tubes. The fraction collector was enclosed in an acrylic plastic chamber with evaporation pans filled with deionized water to minimize evaporation before sample analysis (Fig. 2). A more detailed description of column construction is provided in Dittrich et al. (2015b).

Columns were wet-packed (Dittrich and Reimus, 2015) with $5.0 \mathrm{~g}$ of dry FFM (or no fill for control columns) and the flow rate was set to $0.3 \mathrm{~mL} \mathrm{~h}^{-1}$. The columns were initially flushed with Am-, tritium-, and colloid-free SZW for 7 days and the $\mathrm{pH}$ was monitored to ensure effluent $\mathrm{pH}$ stabilized within $0.1 \mathrm{pH}$ units of the influent solution $(\mathrm{pH} 8.0 \pm 0.1)$ and colloid release from 
the FFM was negligible (within 5\% turbidity of high purity water) before the start of the radionuclide/colloid injection.

To begin each breakthrough experiment, the background solution was switched to a suspension containing tritium and bentonite colloids with sorbed Am. Syringes were refilled several times during the experiment and were eventually changed to tritium-, Am-, and bentonite- free SZW to observe the flushing of the colloids and Am from the columns. Samples were collected at $12 \mathrm{~h}$ intervals and the sample mass was weighed with a digital balance (Mettler, PL1200) and subtracted from the empty test tube weight to calculate the actual flow rates. Total and dissolved Am activity, tritium activity, and colloid concentration were measured for every sample early in the breakthrough and every other sample after breakthrough to ensure adequate effluent was available for reinjection. Unanalyzed effluent was stored in a Teflon ${ }^{\circledR}$ bottle for injection into a subsequent column. The first column injection was conducted in two duplicate columns so that more effluent would be available for subsequent injections. The effluent $\mathrm{pH}$ was measured for one of the duplicate columns. The combined effluent was then injected into another FFM-filled column that had not been previously exposed to colloids or Am. This process was repeated again, with the unanalyzed effluent from the second FFM injection being injected into a third FFM-filled column. A control column was run in parallel with each successive FFM injection. A flowchart of the procedure is shown in Figure 3.

\subsection{Interpretive Modeling}

The column transport data were interpreted using the RELAP2.0 semi-analytical model (Reimus et al., 2003), which simulates 1-D advective-dispersive transport with colloid filtration and colloid-facilitated solute transport. With RELAP2.0, colloid filtration is treated as a linear first-order irreversible process with unlimited site capacity for colloids on immobile column 
surfaces, and the only process considered for colloid-facilitated transport is solute desorption from the colloids, which is treated as a first-order linear process that effectively results in irreversible adsorption of the solute onto immobile column surfaces once the solute is desorbed. We were prepared to use numerical models that relaxed these assumptions if poor fits to the data were obtained, but we found that this relatively simple semi-analytical modeling approach simulated the column data quite well without the need for additional processes. The governing equations for transport of tritium (Eq. 1), colloids (Eq. 2), and Am (Eq. 3) are:

$$
\frac{\partial c_{c}}{\partial t}=-v \frac{\partial c_{c}}{\partial x}+D \frac{\partial^{2} c_{c}}{\partial x^{2}}-k_{f} c_{c}
$$

$\frac{\partial c_{A}}{\partial t}=-v \frac{\partial c_{A}}{\partial x}+D \frac{\partial^{2} c_{A}}{\partial x^{2}}-\left(k_{f}+k_{d}\right) c_{A}-$

where, $t=$ time, $\mathrm{h}$ $c=$ tritium concentration in aqueous phase, $\mathrm{mol} \mathrm{mL}^{-1}$ $c_{c}=$ colloid concentration in aqueous phase, $\mathrm{mol} \mathrm{mL}^{-1}$ $c_{A}=$ Am concentration adsorbed on mobile colloids, $\mathrm{mol} \mathrm{mL}^{-1}$ $k_{f}=$ filtration rate constant for colloids, $\mathrm{h}^{-1}$

$k_{d}=$ desorption rate constant for Am from colloids, $\mathrm{h}^{-1}$ $v=$ water flow velocity, $\mathrm{cm} \mathrm{h}^{-1}$ $D=$ solute and colloid dispersion coefficient, $\mathrm{cm}^{2} \mathrm{~h}^{-1}$

The model was first used to fit the normalized tritium breakthrough curves (Eq. 1) to

determine the mean water residence time and longitudinal dispersion coefficient (or Peclet number, the column length divided by dispersivity) in each column. These parameters were then assumed to apply to the colloids so that a colloid filtration rate constant could be estimated by fitting the colloid breakthrough curves (Eq. 2). Finally, the Am breakthrough curves were fitted in a similar manner as the colloids, with the Am desorption rate constant added to the colloid filtration rate constant and adjusted to fit the Am data. This last step was based on the assumption that the observed reduction in Am concentration was the result of both Am 
desorption from the colloids and the filtration of colloids to which Am was adsorbed. As noted above, it is implicitly assumed that any Am that desorbs from the colloids rapidly adsorbs to immobile FFM surfaces and is effectively removed from the system because of the relative abundance of the FFM surfaces compared to the colloid surfaces.

\section{Results}

\subsection{Control Experiments}

Batch and flow-through control experiments were performed to examine potential removal of Am by the containers, column tubing, and syringes. In the absence of bentonite colloids, dissolved Am was strongly adsorbed to the different containers used for testing. In batch experiments, we find that Teflon bottles remove up to $75 \%$ of the Am present in solution within 3 hours (see experimental details and Fig. B.1 in Appendix B). Shaking the bottles had no measureable effect on the Am concentrations, leading us to conclude that precipitation of Am was an unlikely cause of this loss of Am. Similar testing with experimental materials show significant Am removal by Teflon ${ }^{\circledR}$, polystyrene, and polycarbonate centrifuge tubes (Fig. B.2). When bentonite colloids were present, over $99 \%$ of added Am remained in suspension with $97 \%$ sorbed to colloids and 3\% in the aqueous phase (Fig. B.1). These results led us to focus on the transport of the Am/bentonite suspensions through FFM and not conduct dissolved Am batch and column experiments (because of the large amounts of adsorption to experimental material surfaces that would have to be corrected for).

A series of column breakthrough control experiments (using all experimental materials except the FFM) with Am/bentonite suspension was also conducted. As described in Section 2.6., the stock suspension was injected through a control column and the effluent from the first FFM column was injected into a second control column. FFM breakthrough experiments were 
normalized for the loss of Am in the control experiments and the results of the control breakthrough experiments are shown in Figure 4.

Duplicate columns were used for the first control experiment and are shown in the top and middle graphs. The syringes were refilled after 40,59 , and $74 \mathrm{~mL}$ of cumulative volume and the same syringe was used without rinsing. The noticeable increases in Am concentration after each syringe filling suggests that Am that is initially sorbed to the bentonite is being stripped by the Teflon ${ }^{\circledR}$ in the system until the Teflon ${ }^{\circledR}$ capacity is reached and no more Am is lost from the solution. The loss of Am in the dissolved Am batch experiments and in the syringes during the column experiments indicates that Teflon ${ }^{\circledR}$ does have some affinity for Am at pH 8.0. Further experiments were conducted with the syringes that confirmed that after replacing the Am/bentonite suspension in the syringes 5 times, the loss of Am to the system was reduced to less than 5\% (Fig. B.3.). The same syringes were used for the first, second, and third injections; therefore, only the first injection results show noticeable Am loss to the Teflon ${ }^{\circledR}$ that needed to be corrected for in the breakthrough experiments with FFM. After switching to colloid- and Amfree SZW, the colloid concentrations decrease very fast, although the first column (Fig. 4) shows an increase after the initial drop. The Am has a higher normalized concentration in the tail than tritium which indicates a slow release of Am from the system.

\subsection{Column Breakthrough Experiments}

The column results where a pre-equilibrated suspension of Am and bentonite colloids was passed through a series of three identical columns filled with FFM are shown in Figure 5. The colloid breakthrough occurred within the first pore volume and closely matched the conservative tracer, except the tritium tracer reached $C / C_{0}$ of 1.0 while the colloid breakthrough reached a plateau greater than $C / C_{0}$ of 0.95 but below 1.0. The concentration of Am in the effluent was at $\sim 60 \%$ of the initial concentration when corrected for control column losses. The Am 
transported through the column was mostly adsorbed to the bentonite colloids with $2-3 \%$ of the measured Am being in the dissolved phase and remaining in the sample after centrifugation. After the injection solution was switched to tritium-, Am-, and bentonite-free solution, the colloid counts and Am concentrations decreased very rapidly, matching the behavior of the tritium tracer. The total Am concentration in the breakthrough tail samples was less than $2 \%$ of the influent concentration. The behavior of the Am breakthrough was distinctly different from that of the control columns without FFM. The Am concentrations after switching to colloid- and Am-free water in the control columns had a long tailing that lasted for $\sim 50 \mathrm{~mL}$ during which Am was slowly released from the column. In contrast, the presence of FFM greatly reduced the tailing effect. This indicates that the FFM is the main component of the system that retains Am and perhaps attenuates the effect of the column material's influence on Am transport.

Near the end of the first column experiment (Pass 1), both columns were tapped on the side to examine if any air bubbles were trapped within them. It can be seen in Figure 5 that a significant pulse of colloids exited the column for the next few pore volumes. This was expected as disturbances (mechanical, acoustic, etc.) are known to enhance colloid mobilization (Mohanty et al., 2015; Roberts and Abdel-Fattah, 2009). There was not; however, a corresponding pulse of Am. The injection of an acidic solution of $0.1 \mathrm{M} \mathrm{HCl}$ was able to remobilize most of the remaining Am retained in the column with recovery of $58.9 \%$ and $98.8 \%$ before and after the acid injection, respectively.

For the second and third injections, the $C_{0}$ values used were the aggregate effluent Am and colloid concentrations from the previous column effluent. The normalized Am concentrations in the effluent solutions for the second and third injections were 0.57 and 0.58 , respectively, which were very similar to the $0.58-0.60$ observed for the first injection. The amount of dissolved Am 
in the effluent increased from the first to the third injections. Less than 2-3\% of the total Am was in the dissolved phase for the first injection, and this increased to $5-10 \%$ for the second injection and $10-15 \%$ for the third injection. The second and third injections experiments (pass 2 and 3) do not show significant Am tailing, which is consistent with the first injection observations. Mass balances, $\mathrm{pH}$, and measured flow rates for all experiments are shown in Table 4.

\subsection{Model Analysis}

The model results of the FFM breakthrough experiments are shown in Figure 6. Due to the extremely low concentrations of total Am in the release tails, only the breakthrough portion of the fitted data is shown. Fitted parameters from the model are listed in Table 5. The Am fits for the first pass (in duplicate) assume a gradually increasing injection concentration of Am that is consistent with the increase in outlet concentrations observed in the first passes of the control experiments (Fig. 4). This model correction is based on the Am retardation observed from system components in the control experiments and was treated as a variable $C_{0}$, with the injection function increasing over the course of the injection to match the effluent concentrations from the control experiments. This correction is necessary to enable more accurate modeling of the retardation attributed to the FFM in the column and remove retardation attributed to the column components (i.e., tubing and syringe). The injection concentration of Am was assumed to be equal to $C_{0}$ by the end of the injections in the first pass(es) of the FFM experiments because these injections were $\sim 50 \%$ longer than the control injections, and the Am outlet concentrations by the end of the control experiments had nearly reached $C_{0}$. This correction for attenuation of Am by column system components was not considered necessary for the second and third passes in the FFM experiments because the second pass in the control experiments did not exhibit an increasing Am outlet concentration. The gradual rise in the modeled Am concentrations for the 
first passes in Figure 6, and the very flat modeled Am concentrations (after an initial breakthrough) in the second and third passes reflect these different assumptions for the injection concentrations of Am in each pass.

We did not attempt to account for the colloid and Am tailing in the control experiments when interpreting the FFM experiments. The tailing in the control experiments likely reflects greater hydrodynamic dispersion in the empty columns than in the columns packed with FFM (also apparent from the slower rise in concentrations during injection), and probably also reflects a small amount of colloid detachment and Am desorption from system components. However, any detachment or desorption from system components was clearly suppressed by rapid interaction of the colloids and Am with FFM.

\section{Discussion}

Three criteria are important for colloids to increase the transport of radionuclides such as Am: (1) colloids must be mobilized, (2) mobile colloids must be transported long distances and (3) radionuclides must associate strongly with mobile colloids (DeNovio et al., 2004). It is well established that FEBEX bentonite used as barrier and backfill material generates colloidal bentonite particles. The results presented here show that the negatively charged bentonite particles are extremely mobile in the fracture fill material at the GTS. This is expected based on DLVO theory since the FFM mineral surfaces are also negatively charged at $\mathrm{pH} \geq 8$ and thus there are repulsive electrostatic forces between the colloids and porous media surfaces. Each pass through the columns resulted in nearly identical transport without evidence for aggregation, straining, or preferential attachment of colloids or changes in the adsorption/desorption behavior of the Am. Colloid breakthrough occurred slightly ahead of the conservative tritium tracer which is evidence for size-exclusion or a size chromatography effect (Delos et al., 2008; Schäfer 
et al., 2004), which prevented the colloids from diffusing into or advecting through the smallest pores. After switching to Am-free SZW, colloid concentrations rapidly decreased to nearly background with almost no tailing, indicating that most of deposited colloids were irreversiblyattached in the column, likely due to straining in narrow pore throats. After tapping the side of the column, a large pulse of colloids was mobilized without a corresponding Am pulse which indicates that the FFM is able to strip most of the Am from the bentonite colloids when the system has sufficient residence time. Although the turbidimetric method of measuring colloid concentration does not allow for interrogating the colloid composition, it is believed that the large pulse of colloids was injected bentonite and not inorganic colloids mobilized from the FFM during the course of the injection. No similar observation of a colloid pulse was made in preliminary experiments where columns were equilibrated with bentonite-free SZW for 7 days and tapped to check for air bubbles. The removal of $<75 \mu \mathrm{m}$ particles and the thorough rinsing of FFM with high purity water before column packing also makes it highly unlikely that the observed colloid pulse was derived from the FFM.

The consistency of the model-deduced Am desorption rate constants for each of the column passes suggests that Am adsorption and desorption behavior on the bentonite colloids is well described by a single type of adsorption site. If the desorption rate constant had decreased significantly with each pass (i.e., a higher recovery of Am with each pass), then it would be logical to conclude that Am adsorbed to different types of colloid sorption sites with different effective desorption rate constants. Alternatively, an aging process might be implicated in which Am that is adsorbed to colloids for longer times tends to become more strongly associated with the colloids and thus desorbs more slowly with time (Weiss et al., 1998). The fast desorption process observed also supports the chemical modeling described in Section 2.4, which indicates 
that under our experimental conditions Am is adsorbed and not precipitated on the surface of the colloids due to oversaturation or chemical instability. Interestingly, the single-site adsorption/desorption behavior deduced from modeling the column experiments is in agreement with the conclusion that a single-site model provided the best description of colloid-facilitated Am transport behavior in a Grimsel Test Site field experiment (Wang et al., 2014b).

Modeled batch desorption rates by Flügge et al. (2010) and Huber et al. (2011) for initial Am concentrations of $1.4 \times 10^{-9} \mathrm{M}$ and $8.0 \times 10^{-9} \mathrm{M}$ adsorbed to the colloids were $0.009 \mathrm{hr}^{-1}$ and $0.0037 \mathrm{hr}^{-1}$, respectively. The lower rate of Huber et al. (2011), which corresponds to the initial concentration that is closest to our initial concentration of $5.5 \times 10^{-10} \mathrm{M} \mathrm{Am}$, is about an order of magnitude lower than the rates we estimated in our column experiments (Table 5). However, the solid mass to solution volume ratio of Huber et al. (2011) was $1.0 \mathrm{~g}$ FFM to $4 \mathrm{~mL}$ of solution, whereas in our columns this ratio was approximately $1.0 \mathrm{~g}$ FFM to $0.3 \mathrm{~mL}$; i.e., about one order of magnitude higher in our experiments. The reported BET surface area of the FFM material used by Huber et al. (2011) was in very good agreement with our FFM surface area measurements. When the rate constants are normalized to either the FFM mass to solution volume ratio or the FFM surface area to solution volume ratio, the rate constants in the two sets of experiments are in excellent agreement; i.e., around 0.002 to $0.003 \mathrm{~mL} \mathrm{~g}^{-1} \mathrm{hr}^{-1}$ in both sets of experiments. This good agreement was obtained despite the fact that the experiments of Huber et al. (2011) were conducted under reducing conditions and at a pH closer to the ambient Grimsel test site $\mathrm{pH}$ of 9, whereas our experiments were conducted under oxidizing conditions and at a $\mathrm{pH}$ of 8 . This result suggests that the adsorption-desorption behavior of Am is relatively insensitive to redox conditions and $\mathrm{pH}$ over the ranges of these conditions used in the two studies. 
Although we did not observe different colloid filtration rates or different Am desorption rates in the sequential column injections of this study, this experimental and modeling approach has the potential to effectively interrogate slow kinetic processes associated with colloid-facilitated radionuclide transport. An increase in colloid recoveries in successive column injections would have suggested a fraction of colloids that are relatively susceptible to filtration, and the colloids that remain mobile in later injections would have smaller apparent filtration rate constants that are more relevant for large-scale risk assessment calculations. Similarly, an increase in colloidfacilitated radionuclide recoveries in successive column injections would have suggested multiple types of adsorption sites on colloids with different desorption rates or perhaps bondaging processes that cause the radionuclide to be more strongly associated with colloids over time. In either case, if smaller desorption rate constants were observed with each successive column injection, this approach will allow for interrogation of the stronger radionuclide-colloid interactions that are most relevant to colloid-facilitated transport over long time and distance scales.

\section{Conclusion}

Americium colloid-facilitated transport in the Grimsel FFM system appears to be governed by the desorption of Am from a single type of binding site on the bentonite colloids. In a series of three sequential column injections, the normalized Am effluent concentration $\left(C / C_{0}\right)$ leveled off at between 0.58 and 0.60 even though the concentration of Am being injected into the column was reduced by $46 \%$ and $65 \%$, between the first and second and second and third injections, respectively. These results indicate that the desorption rate constant for Am from the colloids did not change with time, with overall Am concentration, or with the ratio of colloid to Am concentrations. Bentonite colloid breakthroughs in all three repeat column injections were 
consistent and reproducible with nearly complete recoveries ( $k_{f}$ between 0.01 and $0.02 \mathrm{~h}^{-1}$ ), suggesting that there is not a significant fraction of colloids that are highly prone to filtration. Our experiments show that although bentonite colloids were highly mobile, the Am that was sorbed to them was readily desorbed and would not pose a significant transport risk if leaked from a repository with oxidizing $\mathrm{pH} 8$ groundwater and the absence of other competing radionuclides (i.e., the third of the three criteria listed at the beginning of Section 4 for colloidfacilitated transport is not met for the Am-bentonite-FFM system).

\section{Appendices}

\subsection{Appendix A. Sodium Saturation and Bentonite Colloid Processing}

A FEBEX bentonite brick was crushed as sieved and $20 \mathrm{~g}$ of $<75 \mu \mathrm{m}$ material was added to $800 \mathrm{~mL}$ of $1.0 \mathrm{M} \mathrm{NaCl}$ and placed on a shaker table for 7 days. The suspension was decanted and the supernatant was removed and replaced with fresh $1.0 \mathrm{M} \mathrm{NaCl}$ for 7 additional days of agitation. This process was repeated 3 times and the solution conductivity was measured (VWR Series 500, Model 2052 meter and VWR 525 conductivity dip cell/electrode, Model 23198-020) to ensure stability. The resulting suspension was settled and the supernatant was decanted and replaced with SZW. This process was repeated 6 times until the conductivity of the supernatant was reduced below $2.5 \mathrm{mS} \mathrm{cm}^{-1}$ and the colloids did not readily settle. The suspension was then placed in a sonic bath for 30 minutes, centrifuged at $8900 \mathrm{~g}$ for $3.5 \mathrm{~h}$, and the supernatant removed and replaced with SZW. This process was repeated 10 times until the resulting conductivity of the bentonite suspension was within $1 \%$ of the SZW. Images of the process are shown in Figure A.1. 

for 2 weeks to obtain a stable experimental suspension (Figure A.1). The top $700 \mathrm{~mL}$ was decanted and measured for particle size distribution (Figure A.2)

\subsection{Appendix B. Americium Stock Solution Preparation and Control Experiments}

Initial stock solutions of $5.5 \times 10^{-10}$ M Am ( 1000 Decays Per Minute or DPM) were prepared by adding a small spike of concentrated dissolved ${ }^{241} \mathrm{Am}(25 \mu \mathrm{L})$ to $800 \mathrm{~mL}$ of $\mathrm{SZW}$ in a 1 L Teflon ${ }^{\circledR}$ bottle. An $800 \mathrm{~mL}$ stock suspension of $100 \mathrm{mg} \mathrm{L}^{-1}$ bentonite colloids, SZW, and ${ }^{241} \mathrm{Am}$ was also prepared. $1 \mathrm{~mL}$ samples were collected and measured for Am activity at specified intervals, with the results shown in Figure B.1.

Almost $75 \%$ of the Am in the dissolved stock solutions was lost to the Teflon ${ }^{\circledR}$ bottle surface within the first 3 hours, and the solution stabilized to a consistent concentration after $23 \mathrm{~h}$ (note that one of the two stock solutions in Figure 6 appears to take longer than $3 \mathrm{~h}$ to reach $75 \%$ adsorption, but no samples were taken from this bottle until over $100 \mathrm{~h}$ after the first very rapid sample). Shaking the bottles had no measureable effect on the Am concentrations, leading us to conclude that precipitation of Am was an unlikely cause of this loss of Am. When bentonite colloids were present, all of the Am remained in the suspension.

Control experiments with various experimental materials were conducted with a $1.4 \times 10^{-10}$ M dissolved Am solution (245 DPM). This was the same solution that had equilibrated with the Teflon ${ }^{\circledR}$ bottles (Fig. B.1). $15 \mathrm{~mL}$ of solution were added to $50 \mathrm{~mL}$ Teflon ${ }^{\circledR}$ Oak Ridge centrifuge tubes, $50 \mathrm{~mL}$ Teflon ${ }^{\circledR}$ syringes, and $50 \mathrm{~mL}$ polycarbonate test tubes. $8 \mathrm{~mL}$ of solution was added to $8 \mathrm{~mL}$ polystyrene test tubes and $15 \mathrm{~mL}$ polypropylene centrifuge tubes. $1 \mathrm{~mL}$ samples were removed at specified time intervals and measured for dissolved Am activity by 
LSC. All experiments were conducted in duplicate, with the averaged results shown in Figure B.2.

All materials resulted in a significant loss of Am from solution. Polystyrene and polycarbonate materials resulted in the least amount of Am loss while polypropylene and Teflon ${ }^{\circledR}$ resulted in the most loss. These results led us to focus on the transport of the Am/bentonite suspensions through FFM and not conduct dissolved Am batch and column experiments (because of the large amounts of adsorption to experimental material surfaces that would have to be corrected for).

Control experiments were also conducted with $5.5 \times 10^{-10} \mathrm{M} \mathrm{Am}$ and $100 \mathrm{mg} \mathrm{L}^{-1}$ bentonite colloids in two Teflon ${ }^{\circledR}$ syringes. Syringes were filled with Am/bentonite suspension, sampled after $67 \mathrm{~h}$, then emptied and refilled with fresh suspension and the process repeated. Bentonite concentrations remained close to the stock solution for each filling (results not shown). Although $30 \%$ of the Am was lost to the Teflon ${ }^{\circledR}$ in the first filling, less than $5 \%$ of the Am in the suspension was lost to the syringes by the fifth filling (Fig. B.3.).

\section{Acknowledgements}

The authors would like to thank Artaches Migdissov for HCh geochemical speciation modeling and Michael Cheshire and Hongwu Xu for conducting the quantitative X-ray diffraction analyses of the Grimsel materials. We also thank Ingo Blechschmidt of the Swiss Nuclear Waste Cooperative, NAGRA, for providing the granodiorite and FFM materials. This work was supported by the U.S. DOE Nuclear Energy Office, Fuel Cycle R\&D Program, Used Fuel Disposition Campaign, which is administered by Sandia National Laboratories. The authors greatly appreciate the valuable comments provided by the editor and two anonymous reviewers. 


\section{References}

Baston, G.M.N., Berry, J.A., Brownsword, M., Heath, T.G., Tweed, C.J., Williams, S.J., 1994. Sorption of plutonium and americium on repository, backfill, and geologic materials relevant to the JNFL low-level radioactive waste repository at Rokkasho-Mura. Mat. Res. Soc. Proc. 353, 957-964.

Bastrakov, E.N., 1999. HCh: a software package for geochemical equilibrium modelling. User's guide. Record 1999/025. Australian Geological Survey Organization, Canberra.

Bradbury, M.H, Baeyens, B., 2009. Sorption modelling on illite. Part II: Actinide sorption and linear free energy relationships. Geochim. Cosmochim Acta 73, 1004-1013.

Bradbury, M.H, Baeyens, B., 2006. Modelling sorption data for the actinides Am(III), Np(V) and $\mathrm{Pa}(\mathrm{V})$ on montmorillonite. Radiochim. Acta. 94(9-11), 619-625.

Bradbury, M.H, Baeyens, B., 2005a. Modelling the sorption of Mn(II), Co(II), Ni(II), Zn(II), $\mathrm{Cd}(\mathrm{II}), \mathrm{Eu}(\mathrm{III}), \mathrm{Am}(\mathrm{III}), \mathrm{Sn}(\mathrm{IV}), \mathrm{Th}(\mathrm{IV}), \mathrm{Np}(\mathrm{V})$ and U(VI) on montmorillonite: Linear free energy relationships and estimates of surface binding constants for some selected heavy metals and actinides. Geochim. Cosmochim Acta 69(4), 875-892.

Bradbury, M.H, Baeyens, B., 2005b. Experimental measurements and modeling of sorption completion on montmorillonite. Geochim. Cosmochim Acta 69(17), 4187-4197.

Degueldre, C., Ulirich, H.J., Sibly, H., 1994. Sorption of ${ }^{241}$ Am onto montmorillonite, illite, and hematite colloids. Radiochim. Acta. 65(3), 173-179.

Degueldre, C., Bilewicz, A., Hummel, W., Loizeau, J.L., 2001. Sorption behavior of Am on marl groundwater colloids. J. Environ. Radioact. 55(3), 241-253.

Delos A., Walther, C., Shäfer, T., Büchner, S., 2008. Size dispersion and colloid mediated radionuclide transport in a synthetic porous media. J. Colloid Interf. Sci. 324, 212-215.

DeNovio, N.M., Saiers, J.E., Ryan, J.N., 2004. Colloid movement in unsaturated porous media: Recent advances and future direction. Vadose Zone J. 3(2), 338-351.

Dittrich, T.M., 2012. The Role of Desorption Kinetics and Physical Heterogeneity in the Colloid Facilitated Transport of Cesium and Strontium Through an Unsaturated Quartz Porous Medium. PhD Dissertation. Department of Civil and Environmental Engineering. University of Colorado-Boulder, Boulder, CO.

Dittrich, T.M., Reimus, P.W., 2013. Experimental evaluation of actinide transport in a fractured granodiorite. Proceedings of the 14th International High-Level Radioactive Waste Management Conference, American Nuclear Society, LaGrange Park, IL. pp. 473-480.

Dittrich, T.M., Reimus, P.W., 2014. Potential for colloid-facilitated transport of americium in a bentonite/granodiorite system. Abstr. Pap. Am. Chem. Soc. 247, 247 $7^{\text {th }}$ American Chemical Society National Meeting, Dallas, TX, Mar 18, American Chemical Society: Washington, D.C, 2014; 113-GEOC. LA-UR-14-21928.

Dittrich, T.M., Reimus, P.W., 2015. Uranium transport in a crushed granodiorite: Experiments and reactive transport modeling. J. Contam. Hydrol. 175-176, 44-59.

doi: 10.1016/j.jconhyd.2015.02.004. 
Dittrich, T.M., Boukhalfa, T.M., Reimus, P.W., 2015a. Three column series approach to investigate role of desorption rates in colloid-facilitated transport of americium, cesium, and plutonium: Experiments and modeling. Abstr. Pap. Am. Chem. Soc. 249, $249^{\text {th }}$ American Chemical Society National Meeting, Denver, CO, Mar 25, American Chemical Society: Washington, D.C, 2015; 455-COLL. LA-UR-15-22155.

Dittrich, T.M., Ware, S.D., Reimus, P.W., 2015b. Mini-columns for conducting breakthrough experiments: Design and construction. LA-UR-15-24392; Los Alamos National Laboratory, Los Alamos, NM.

Flügge, J. Küntzel, M., Schäfer, T., Gaus, I., Noseck, U., 2010. Modeling colloid-bound radionuclide transport at the Grimsel Test Site. In: International Groundwater Symp. IAHR. Valencia, Spain.

Geckeis, H., Schäfer, T., Hauser, W., Rabung, Th., Missana, T., Degueldre, C., Möri, A., Eikenberg, J., Fierz, Th., Alexander, W., 2004. Results of the colloid and radionuclide retention experiment (CCR) at the Grimsel Test Site (GTS), Switzerland - impact of reaction kinetics and speciation on radionuclide migration. Radiochim. Acta. 92, 765-774.

Huber, F., Kunze, P., Geckeis, H., Schäfer, T., 2011. Sorption reversibility kinetics in the ternary system radionuclide-bentonite colloids/nanoparticles-granite fracture filling material. Appl. Geochem. 26, 2226-2237.

Iijima, K., Tomura, T., Tobita, M., Suzuki, Y., 2010. Distribution of Cs and Am in the solution-bentonite colloids-granite ternary system: effect of addition order and sorption reversibility. Radiochim. Acta 98, 729-736.

Iijima, K., Shoji, Y., Tomura, T., 2008. Sorption behavior of americium onto bentonite colloid. Radiochim. Acta 96, 721-730.

Kersting, A.B., Efurd, D.W., Finnegan, D.L., Rokop, D.J., Smith, D.K., Thompson, J.L., 1999. Migration of plutonium in ground water at the Nevada Test Site. Nature 397, 56-59.

Kunze, P, Seher, H., Hauser, W., Panak, P.J., Geckeis, H.Fanghänel, Th., Schäfer, T. 2008. The influence of colloid formation in a granite groundwater bentonite porewater mixing zone on radionuclide speciation. J. Contam. Hydrol. 102, 263-272.

Kurosawa, S., James, S.C., Mikazu, Y., Ibaraki, M., 2006. Model analysis of the colloid and radionuclide retardation experiment at the Grimsel Test Site. J. Colloid Interf. Sci. 298, 467475.

Liu, J., Neretnieks, I., 2006. Physical and chemical stability of the bentonite buffer. SKB Rapport R-06-103. Svensk Kärnbränslehantering AB.

Marty, R.C., Bennett, D., Thullen, P., 1997. Mechanism of plutonium transport in a shallow aquifer in Mortandad canyon, Los Alamos National Laboratory, New Mexico. Environ. Sci. Technol. 31(7), 2020-2027.

Missana, T., Garcia-Gutierrez, M., Alonso, U., 2004. Kinetics and irreversibility of cesium and uranium sorption onto bentonite colloids in a deep granitic environment. Appl. Clay Sci. 26, 137-150. 
Mohanty, S.K., Bulicek, M.C.D., Metge, D.W., Harvey, R.W., Ryan, J.N., Boehm, A.B., 2015. Mobilization of microshperes from a fractured soil during intermittent infiltration events. Vadose Zone J. 14(1).

Möri, A., Alexander, W., Geckeis, H., Hauser, W., Schäfer, T., Eikenberg, J., Fierz, T., Degueldre, C., Missana, T., 2003. The colloid and radionuclide experiment at the Grimsel Test Site: influence of bentonite colloids on radionuclide migration in a fractured rock. Colloids Surf. A - Physicochem. Eng. Aspects 217(1), 33-47.

Murali, M., Mathur, J., 2002. Sorption characterisitics of Am(III), Sr(II) and Cs(I) on bentonite and granite. J. Radioanal. Nucl. Ch. 254(1), 129-136.

Nagasaki, S., Tanaka, S., Suzuki, A., 1994. Colloid formation and sorption of americium in the water/bentonite system. Radiochim. Acta 66(7), 207-212.

Penrose, R., Polzer, W., Essington, E., Nelson, D., Orlandini, K., 1990. Mobility of plutonium and americium through a shallow aquifer in a semiarid region. Environ. Sci. Technol. 24, 228-234.

Reimus, P. W., Pohll, G., Mihevc, T., Chapman, J., Papelis, L., Lyles, B., Kosinski, S., Niswonger, R., Sanders, P., 2003. Testing and parameterizing a conceptual model for radionuclide transport in a fractured granite using multiple tracers in a forced-gradient test, Water Resour. Res., 39(12), 1350, doi:10.1029/2002WR001597.

Roberts, P.M., Abdel-Fattah, A.I., 2009. Seismic stress stimulation mobilizes colloids trapped in porous rock. Earth Planet. Sci. Lett. 284(3-4), 538-543.

Schäfer, T., Geckeis, H., Bouby, M., Fanghänel, T. 2004. U, Th, Eu and colloid mobility in a granite fracture under near-neautral flow conditions. Radiochim. Acta 92, 731-736.

Schäfer, T., Huber, F., Seher, H., Missana, T., Alonso, U., Kumke, M., Eidner, S., Claret, F., Enxmann, F., 2012. Nanoparticles and their influence on radionuclide mobility in deep geologic formation. Appl. Geochem. 27, 390-403.

Schäfer, T., Noseck, U. (Eds), 2010. Colloid/ Nanoparticle formation and mobility in the context of deep geological nuclear waste disposal. Project KOLLORADO-1; Final report. FZKA 7515, Forschungszentrum Karlsruhe, Karlsrule.

Vilks P., Baik, M., 2001. Laboratory migration experiments with radionuclides and natural colloids in a granite fracture. J. Contam. Hydrol. 47, 197-210.

Wang, Y. Gardner., P., Reimus, P., Painter, S., Makedonska, N., Pollack, A., Houseworth, J., Rutqvist, J., Asahina, D., Chen, F., Vilarrasa, V., Liu, H., Birkholzer, J., Begg, J., Zavarin, M., Kersting, A., Kim, G., 2013a. Natural System Evaluation and Tool DevelopmentInternational Collaborations: FY13 Progress Report, Chapter 2, Interpretations of ColloidFacilitated Transport Experiments at the Grimsel Test Site from 2008 through 2012. FCRDUFD-2013-000628; pp. 5-42.

Wang, Y., Miller, A., Matteo, E., Reimus, P., Ding, M., Dittrich, T., Zheng, L., Houseworth, J., Zhao, P., Kersting, A., Dai, Z., Zavarin, M., 2013b. Experimental and Modeling Investigation of Radionuclide Interaction and Transport in Representative Geologic Media, FCRD-UFD-2013-000314; Chapter 5, An Experimental Methodology for Improving 
Radionuclide Transport Process Models Using Uranium and Grimsel Granodiorite as a Case Study. FCRD-UFD-2013-000314; pp. 47-76.

Wang, Y., E. Matteo, J. Rutqvist, J. Davis, L. Zheng, J. Houseworth, J. Birkholzer, T. Dittrich, C. Gable, S. Karra, N. Makedonska, S. Chu, D. Harp, S. Painter, P. Reimus, F. Perry, P. Zhao, J. Begg, M. Zavarin, S. Tumey, Z. Dai, A. Kersting, J. Jerden, K. Frey, J.M. Copple, W. Ebert., 2014a. Used Fuel Disposal in Crystalline Rocks: Status and FY14 Progress, Chapter 6, Laboratory Investigation of Colloid-Facilitated Transport of Americium by Bentonite Colloids in a Granodiorite System. FCRD-UFD-2014-000060 and SAND201417992 R (UUR); Sandia National Laboratories, Albuquerque, NM. pp. 181-200.

Wang, Y., E. Matteo, J. Rutqvist, J. Davis, L. Zheng, J. Houseworth, J. Birkholzer, T. Dittrich, C. Gable, S. Karra, N. Makedonska, S. Chu, D. Harp, S. Painter, P. Reimus, F. Perry, P. Zhao, J. Begg, M. Zavarin, S. Tumey, Z. Dai, A. Kersting, J. Jerden, K. Frey, J.M. Copple, W. Ebert., 2014b. Used Fuel Disposal in Crystalline Rocks: Status and FY14 Progress, Chapter 7, Evaluation of Alternative Descriptions of Desorption of Tri- and Tetravalent Solutes from Bentonite Colloids in Tracer Tests at the Grimsel Test Site. FCRD-UFD-2014000060 and SAND2014-17992 R (UUR); Sandia National Laboratories, Albuquerque, NM. pp. 201-233.

Weiss, M., Lüthi, Y., Rička, J., Jörg, T., Bebie, H., 1998. Colloidal particles at solid-liquid interfaces: Mechanism of desorption kinetics. J. Colloid Interf. Sci. 206(1), 332-331.

Wold, S., 2010. Sorption of prioritized elements on montmoillonite colloids and their potential to transport radionuclides. SKB Technical Report TR-10-20 Swedish Nuclear Fuel and Waste Management Co (SKB), Stockholm, Sweden. 
Table 1. Americium distribution coefficients reported in the literature from $\mathrm{pH} 8$ to $\mathrm{pH} 10$.

\section{Reference}

Geckeis et al. (2004)

Degueldre et al. (2001)

Nagasaki et al. (1994)

Iijima et al. (2008)

Iijima et al. (2008)

Iijima et al. (2010)

Iijima et al. (2010)

\section{System}

FEBEX bentonite in Grimsel groundwater

Chlorite and illitised smectite

Bentonite and intrinsic colloids

Bentonite

Bentonite

Bentonite

Crushed Grimsel Test Site granite

Distribution pH Coefficient $\left(\mathbf{m}^{\mathbf{3}} \mathbf{k g} \mathbf{- 1}\right)$

$9.6 \quad 1.2-2.7 \times 10^{3}$

$8.6 \quad 1-3 \times 10^{3}$

$-\quad>1 \times 10^{1}$

$8 \quad 4-90 \times 10^{3}$

$10 \quad 5-20 \times 10^{4}$

$9.6 \quad 7.6-8.7 \times 10^{3}$

$9.6 \quad 1-2 \times 10^{1}$

763

764

765

766

Table 2. Synthetic shear zone water constituents.

\begin{tabular}{cr}
\hline Constituent & $\mathrm{mg} \mathrm{I}_{768}^{767}$ \\
\hline $\mathrm{Na}$ & 14.9769 \\
$\mathrm{~K}$ & 0.2070 \\
$\mathrm{Mg}$ & 0.0771 \\
$\mathrm{Ca}$ & 5.6772 \\
$\mathrm{Cl}$ & 5.6773 \\
$\mathrm{SO}$ & 5.8674 \\
$\mathrm{~F}$ & 6.0976 \\
$\mathrm{Si}$ & 9.9677 \\
$\mathrm{CO}_{3}+\mathrm{HCO}_{3}$ & 20.068 \\
\hline Ionic Strength & 0.667779 \\
$\mathrm{pH}$ & 8.0781 \\
\hline
\end{tabular}

Solution concentrations are based on elemental concentrations added to high purity water. 
799

800

801

802

803

804

805

806
Table 3. Quantitative X-ray diffraction interpretation (wt. \%) of Grimsel granodiorite, shear zone surface, and bulk FFM materials.

\begin{tabular}{lccc}
\hline Mineral & Granodiorite & $\begin{array}{c}\text { Shear } \\
\text { Zone } \\
\text { Surface }\end{array}$ & FFM \\
\hline Quartz & 32 & 18 & 13 \\
Microcline & 10 & 8 & 5 \\
Albite & 42 & 44 & 34 \\
Biotite & 5 & 11 & 31 \\
Chlorite & 1 & -- & \\
Muscovite & 10 & 19 & 16 \\
Epidote & $<1$ & -- & -- \\
Smectite & -- & -- & 1 \\
Calcite & -- & $<1$ & $<1$ \\
\hline
\end{tabular}


Table 4. Mass balances, $\mathrm{pH}$, and flow rates for column experiments.

\begin{tabular}{lcccc}
\hline & Pass 1a & Pass 1b & Pass 2 & Pass 3 \\
\cline { 2 - 5 } \% Am recovery before acid & 58.9 & 58.1 & 58.8 & 58.1 \\
\% Am recovery after acid & 98.8 & 98.3 & 102.9 & 97.2 \\
pH $^{\mathbf{a}}$ & $8.02 \pm 0.04$ & - & $8.02 \pm 0.05$ & $8.00 \pm 0.02$ \\
Flow rate $^{\mathbf{a}}\left(\mathbf{m L ~ h}^{-\mathbf{1}}\right)$ & $0.28 \pm 0.01$ & $0.28 \pm 0.01$ & $0.28 \pm 0.01$ & $0.28 \pm 0.01$ \\
\hline
\end{tabular}

${ }^{\mathrm{a}}$ Not including acid flush

Table 5. Parameters deduced from RELAP2.0 model fits to FFM co breakthrough curves.

\begin{tabular}{lcccc}
\hline & Pass 1a & Pass 1b & Pass 2 & Pass 3 \\
\cline { 2 - 5 } $\begin{array}{l}\text { Colloid filtration rate } \\
\text { constant } \boldsymbol{k}_{f}\left(\mathbf{h}^{-1}\right)\end{array}$ & 0.01 & 0.02 & 0.02 & 0.02 \\
$\begin{array}{l}\text { Am desorption rate constant } \\
\text { from colloids } \boldsymbol{k}_{f}\left(\mathbf{h}^{-1}\right)\end{array}$ & 0.094 & 0.097 & 0.098 & 0.091 \\
$\begin{array}{l}\text { Mean residence time (h) } \\
\text { Peclet number }\end{array}$ & 6.5 & 6.5 & 6 & 6 \\
\hline
\end{tabular}




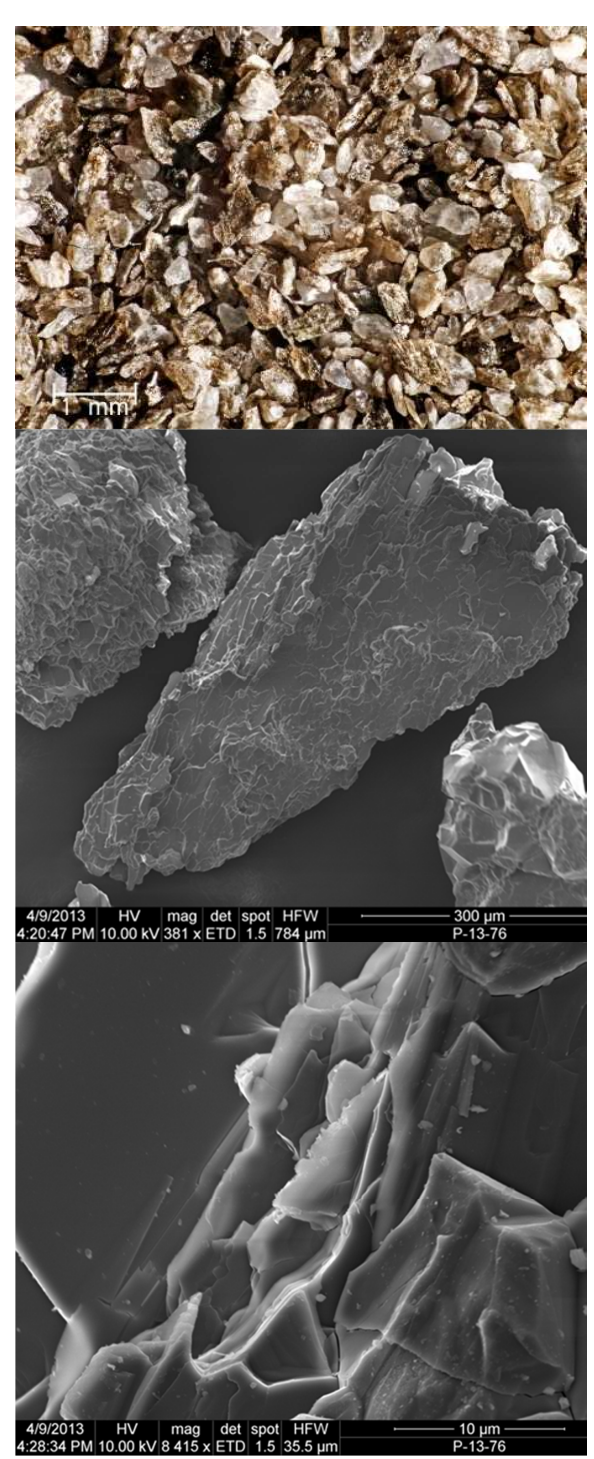

Fig. 1. Images of fracture fill material (150-355 $\mu \mathrm{m}$ size fraction). Microphotograph (top) shows varied shape and color or particles and SEM images of one particle (middle) and edge of particle (bottom) show layering and rough edges. Energy dispersive spectroscopy (EDS) elemental analysis for fracture fill material can be found in Dittrich et al. (2015a). 


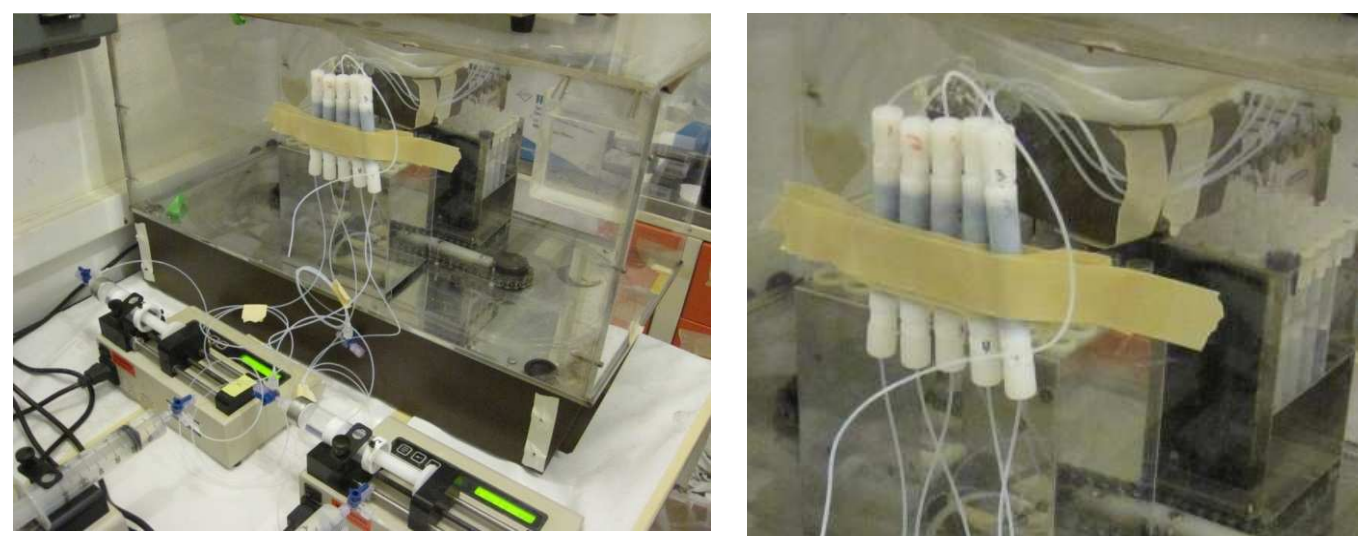

Fig. 2. Photos of column setup with 5 columns running in parallel with syringe pumps, tubing, and fraction collector (left) and closer view of columns (right). 


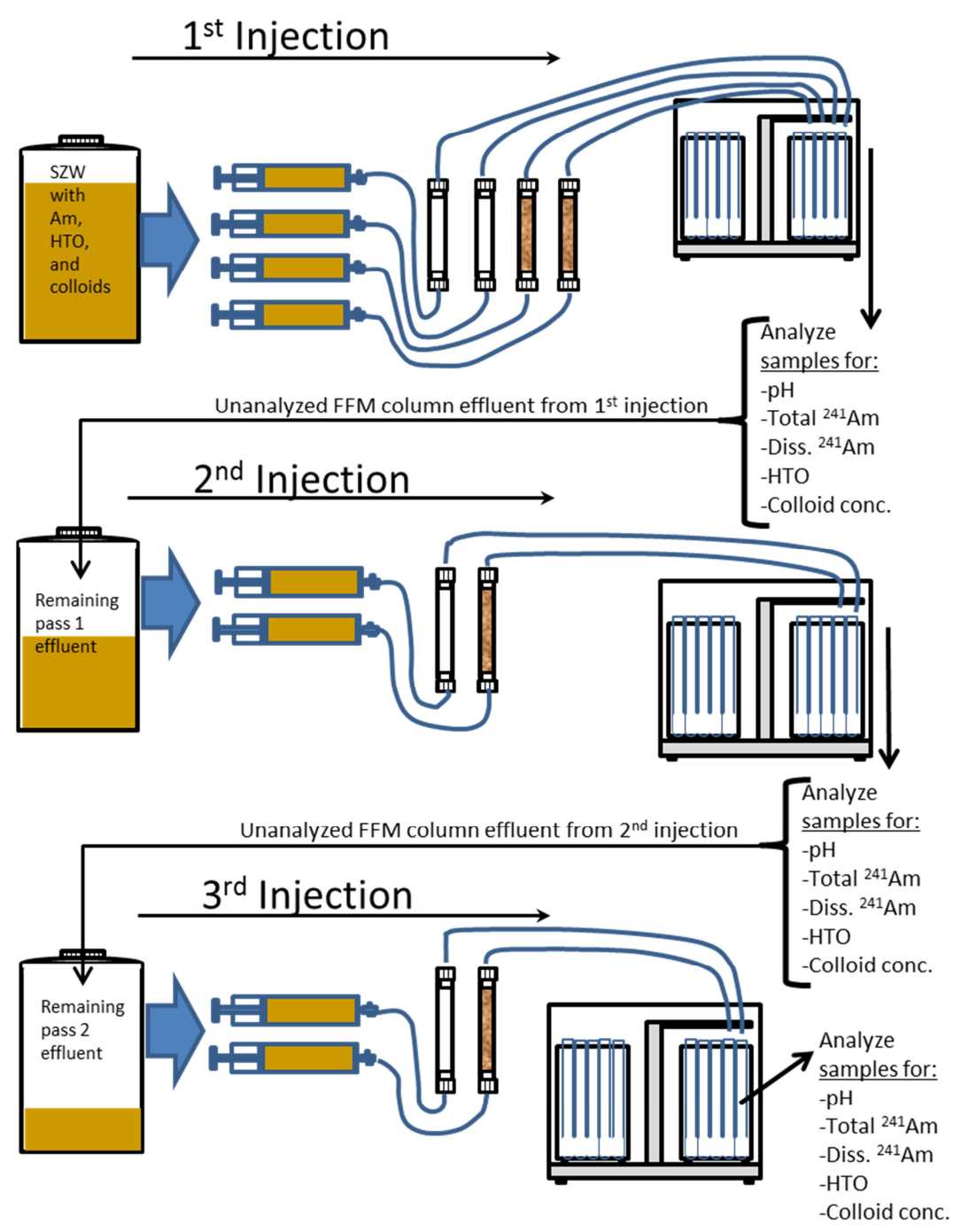

Fig. 3. Flowchart of Am-colloid column experiments. A SZW/bentonite suspension with ${ }^{241}$ Am and HTO added was injected through two columns filled with FFM (brown/grey columns) and two control columns (white). Aliquots of effluent were analyzed for $\mathrm{pH}$, total and dissolved ${ }^{241} \mathrm{Am}, \mathrm{HTO}$, and colloid concentrations and the remaining effluent was combined in a Teflon ${ }^{\circledR}$ bottle and injected through a second column filled with FFM and a second control column. Aliquots of the second injection effluent were measured for the above parameters and the remainder was combined and injected through a third column filled with FFM and a third control column. Aliquots of the third injection were measured for the above parameters. 

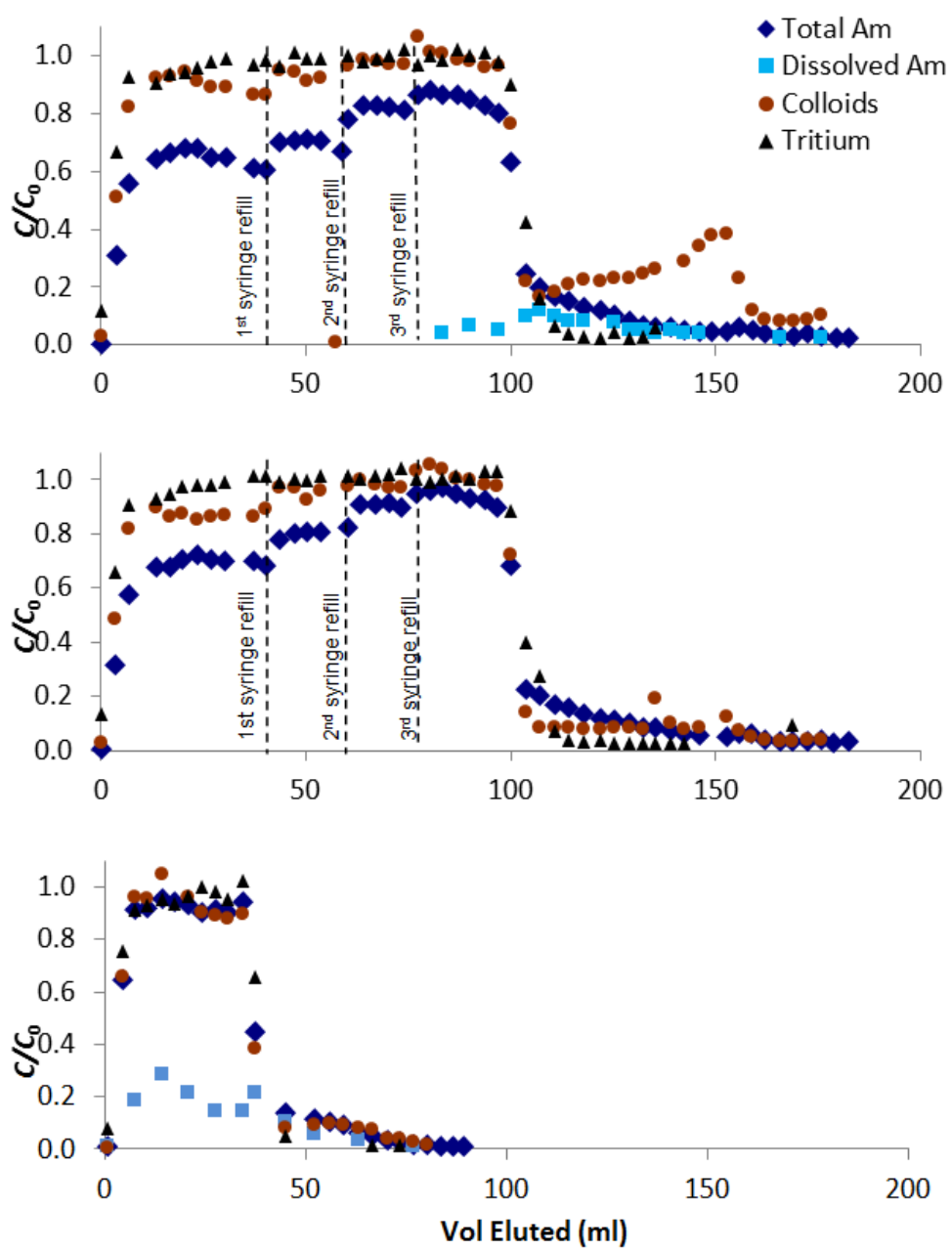

Fig. 4. Results of control breakthrough experiments (system components only with no FFM). The top and middle graphs are duplicate controls for the first pass (stock solution) and the bottom graph is for the second pass (effluent from first FFM column injected through an empty column). The injection concentration $\left(C_{0}\right)$ used for the bottom graph was the composite effluent concentration coming out of the first FFM column. 

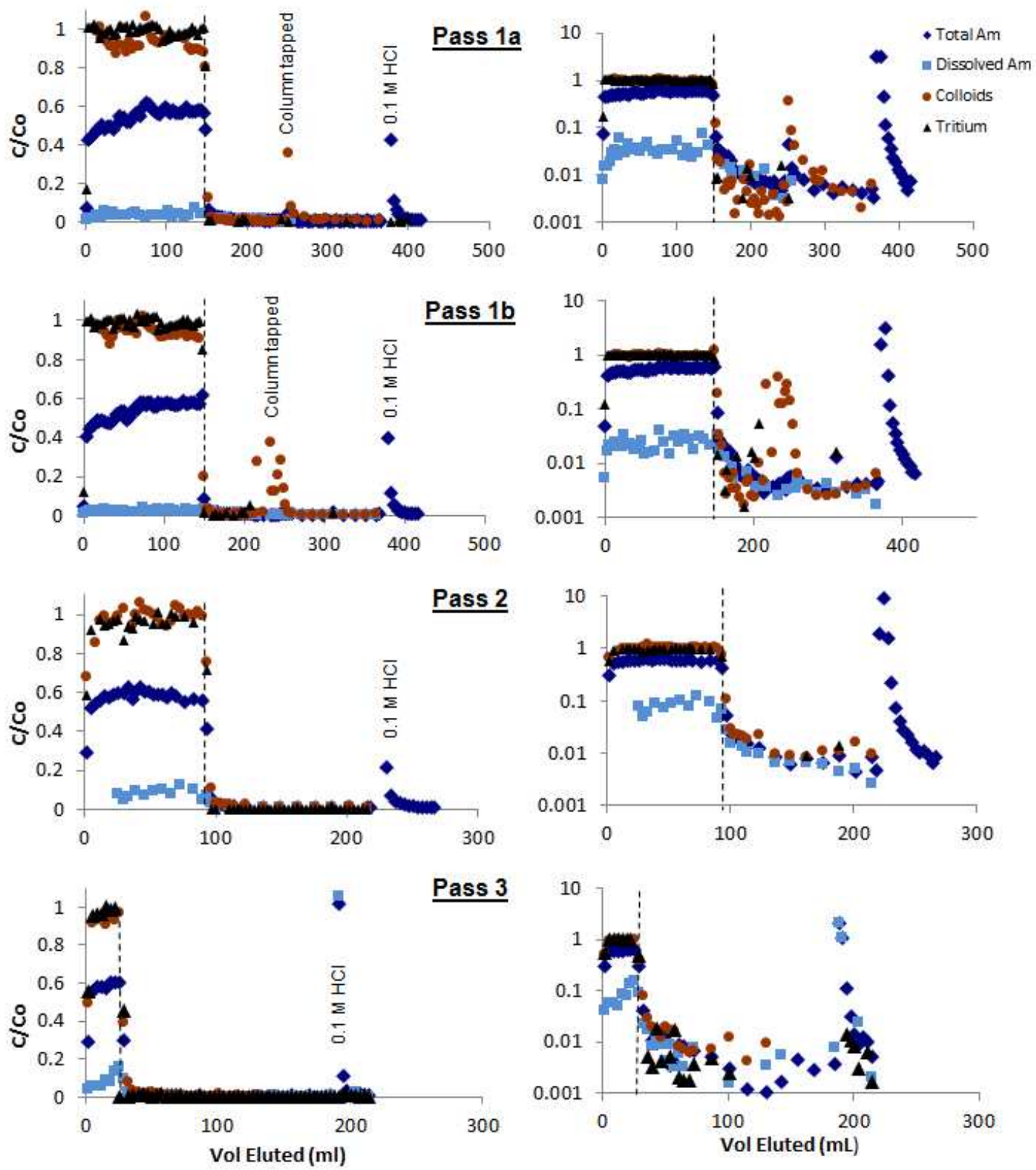

Fig. 5. Results of breakthrough experiments with $C / C_{0}$ on linear scale (left) and log scale (right). The top two rows are duplicate experiments for the first pass of stock solution through FFM (Pass 1a and Pass 1b). The third row is for the second injection, which passed the effluent from the first columns through a new FFM column. The bottom row is for the third pass, which was the injection of effluent from the second pass through a new FFM column. The vertical dashed line denotes when the suspension injection was stopped and injection of americium- and colloidfree SZW was started. 

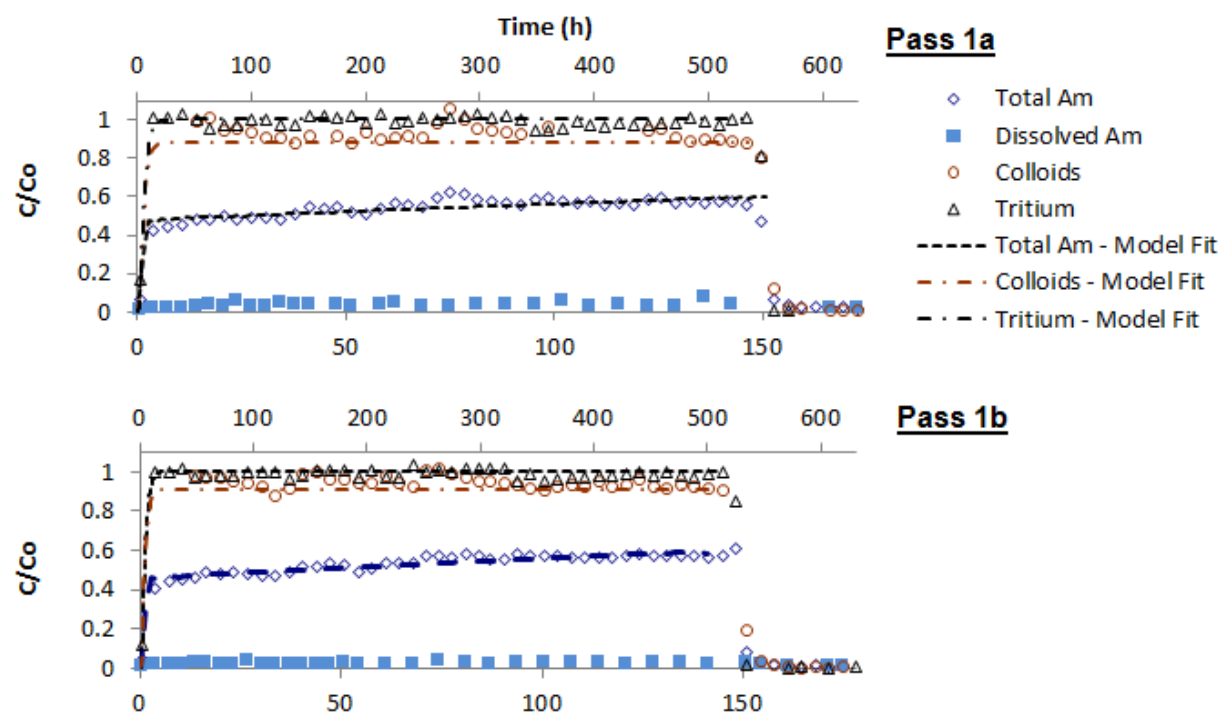

\section{Pass 1b}

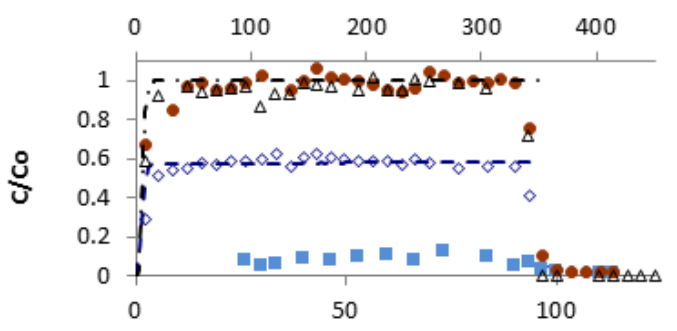

\section{Pass 2}

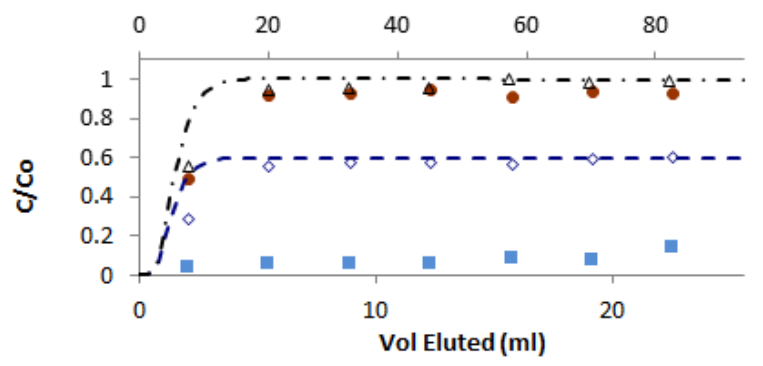

\section{Pass 3}

Fig. 6. Model fits for americium breakthrough experiments with bentonite colloids. Results are shown for the first injection (Pass 1a and Pass 1b), second injection (Pass 2), and third injection (Pass 3). 

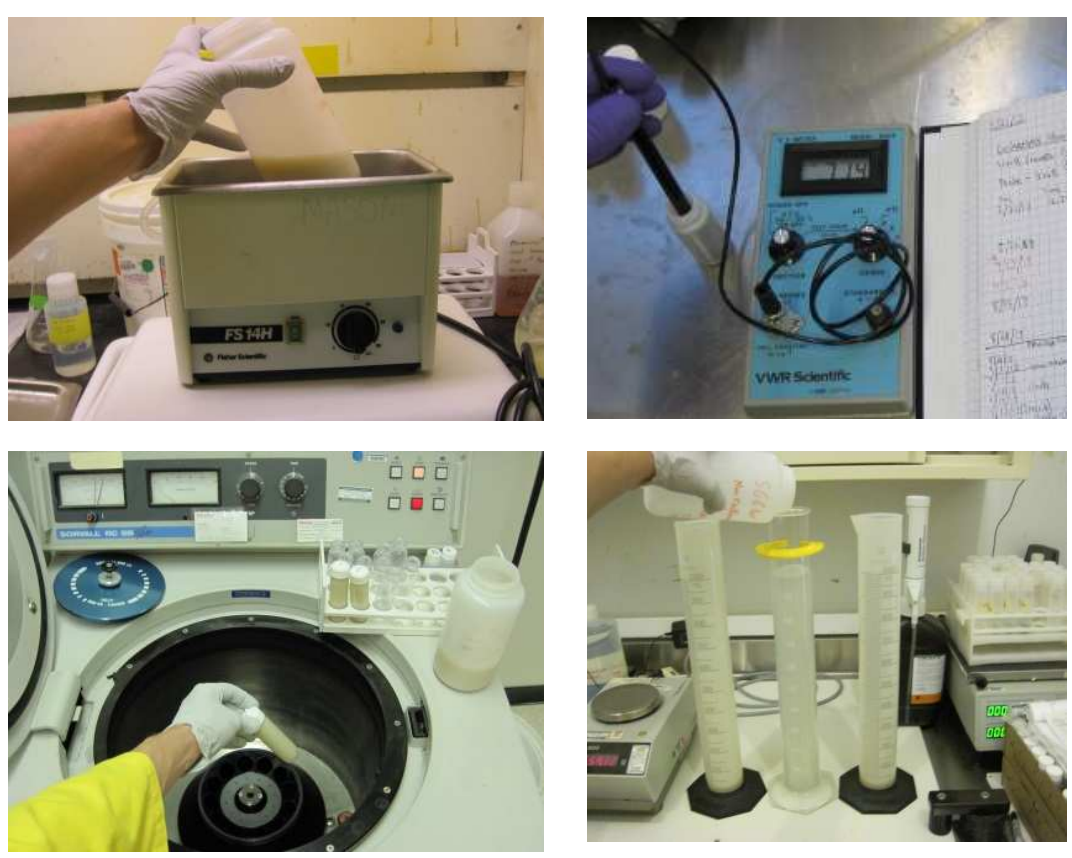

Fig. A.1. Preparation of colloid suspension from FEBEX bentonite brick. Sonication (upper left), conductivity measurement (upper right), centrifugation (lower left), and settling (lower right).

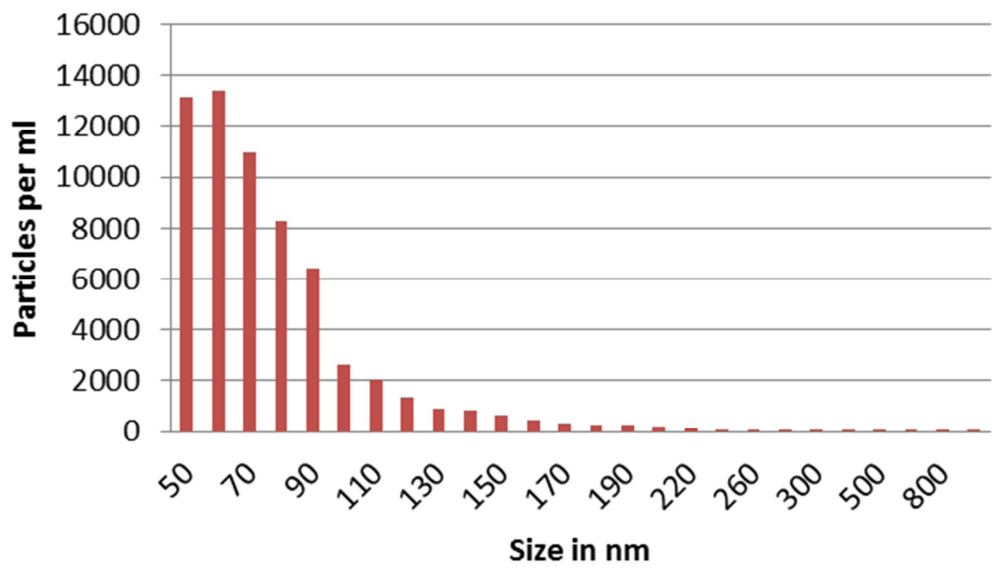

Fig. A.2. Particle size distribution of FEBEX bentonite colloid suspension as measured by a single particle counter. Note that the concentration scale on the y-axis does not account for sample dilution. 


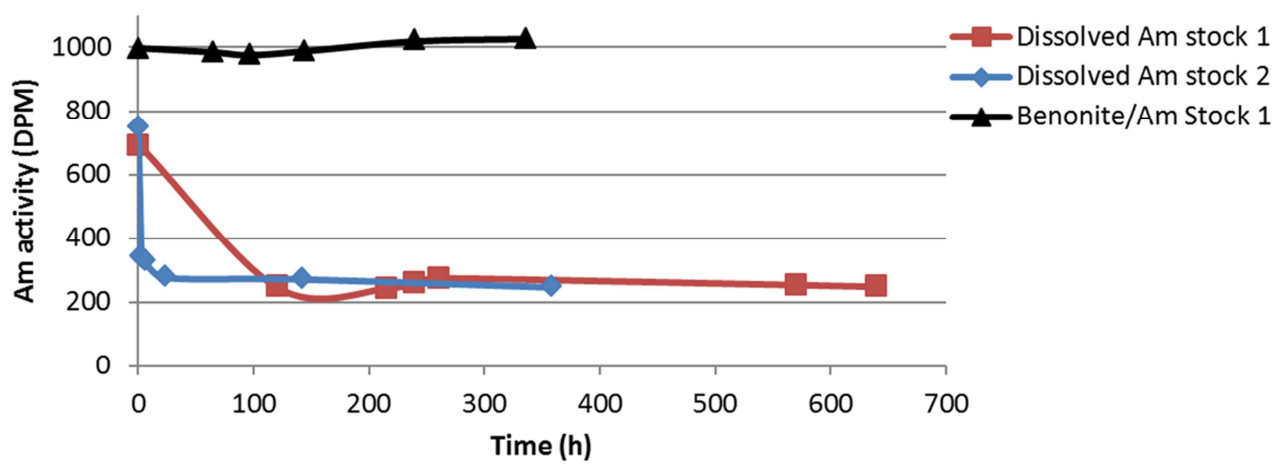

Fig. B.1. Concentration of Am in stock solutions/suspensions stored in Teflon

756

757

758

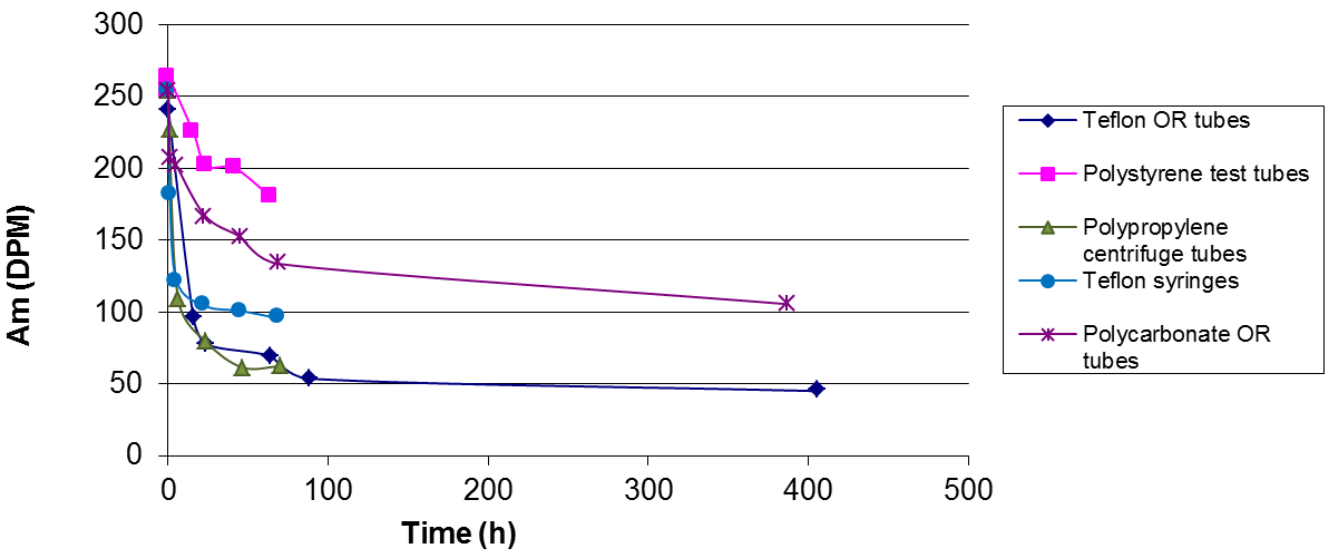

Fig. B.2. Material compatibility with dissolved Am solution. Materials tested were Teflon ${ }^{\circledR}$ Oak Ridge centrifuge tubes, polystyrene test tubes, polypropylene centrifuge tubes, Teflon ${ }^{\circledR}$ syringes, and polycarbonate Oak Ridge centrifuge tubes. 


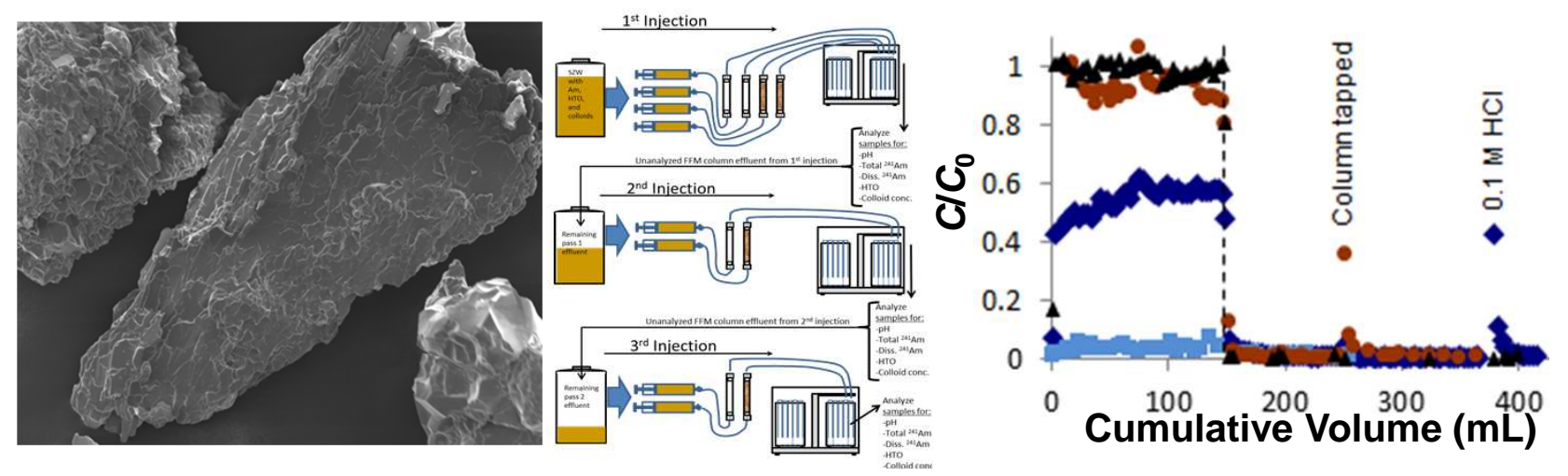

